\title{
Substance Abuse among Females in Nigeria
}

\author{
Adebimpe A. Adenugba \\ Department of Sociology \\ University of Ibadan \\ Folashade B. Okeshola \\ Department of Sociology \\ Ahmadu Bello University \\ Zaria
}

\begin{abstract}
Drug abuse is the indiscriminate use of drugs without a doctor's prescription. Drugs commonly abuse is sleeping tablets, pain relief tablets, cough syrup, household detergents, narcotics and psychotropic substances. Female Involvement in drug abuse starts with experimentation or curiosity, occasional use, regular use and dependency addiction. Reasons advance for drug abuse are peer group influence, psychological or physiological factors, environmental factors, unemployment, unmet expectations and media advertisement. The consequences of drug abuse include mental illness, liver and kidney related diseases, low productivity, child abuse, sexual abuse, loss of individual integrity, financial mismanagement, destruction of family hope and untimely death. This paper will examine the extent of female involvement in substance abuse, commonly abuse drugs, implications of substance abuse on the overall national development. Strategies will be suggested in order to curb the ugly trends of substance abuse among the females in Nigeria.
\end{abstract}

Keywords: Drug, drug abuse, substance abuse, prevalence, experimentation

\section{Introduction}

The current trend of substance abuse among women is a major national concern, it is troubling. It has derogatory effects on women such as health and behavioral problems, or even death. The word 'drug' has been subjected to different definitions. The word drug originates from German word 'drogvate', which literally means "dry casks".

The drug is that substance that, its chemical nature, affects the structure or function of a living organism. This definition covers everything that people ingest, inhale, or absorb. It includes medicines, over - the counter drugs, illegal drugs, beverages, cigarette, food additives, industrial chemicals and even food. Drug abuse is taking of drugs to the extent that they cause social or medical harm to the taker.

\section{Statement of Research Problem}

In recent years, the availability and misuse of illicit substances among the youth (male and female) around the globe, including developing countries like Nigeria remained a serious social problem confronting societies (Fareo, 2012; Emmanuel, 2013; Yunusa, 2016). According to Oshikoya et al (2006), there have been consistent rapid increases in the incidence of substance abuse in Nigeria starting from the 10 years of age. Despite efforts by the National Drug Law Enforcement Agency (NDLEA) and other tiers of government in the country to prevent and control the social problem, it has remained a source of serious law violation and other criminal acts by all categories of users (male and female).

The physical, psychological, social and economic consequences of the drug problems among youth are becoming more obvious and disturbing. Young people who persistently abuse substances often experience an array of problems, including academic difficulties, health related problems (including mental health), poor peer relationships and involvement in social vices such as stealing, bullying, secret cult activities. All these have negative consequences for family members, community and the entire society. Ayatse (2005), reported that the materials needed for initiation of cult members include intoxicating wine prepared with hallucinating drugs such as Indian hemp and cocaine. These drugs will intoxicate the cult members and it will make them to be bold, and under the influence of drugs, they can kill or destroy their mates or lecturers. 
Students gave various reasons. Substance abuse is common among undergraduate students; many of them abuse, substance such as drug, alcohol and tobacco. Alcohol is the most widely used and abused drug among youth, and it causes serious and potentially life threatening problems. For this population, they took drugs to feel happy, excited and friendly, especially to members of the opposite sex. Some said they used drugs for sexual excitements, mental alertness and that drugs give them better visual and auditory experience.

\section{Review of Relevant Literature}

The issue of drug abuse is a common global phenomenon in the contemporary times. The majority of the crimes being committed today are directly or indirectly connected to substance abuse (Siro, 2008). The persistence of drug abuse behavior in urban Kano has become a universal phenomenon, not only among the teeming youth but across all population segments. Preliminary investigation revealed that peer group influence, parenting style, broken homes and law enforcement corruption are some of the factors responsible for drug abuse menace (Siro, 2017). Abdullahi (2003), argued that, drugs are mainly substances that are taken to sedate, excite, slim, arouse, and put to sleep or cure. People usually ingest or inject those drugs into their bodies to achieve these goals. Drug abuse is seen as a problem that is causing serious concern to both individuals and government the world over. It is prevalent among adolescents (male and female) who in most cases are ignorant about the inherent dangers of drug abuse. Many of the abusers engage in the act out of frustration, poverty, lack of parental supervision, peer influence, pleasure etc. (Oluremi, 2012).

According to Yunusa (2016), in his study of substance abused by delinquents (male and female) in Zaria metropolis, found that inhalants or industrial solvents such as glue,/gum solution, gasoline/petrol, nitrous oxide and laughing gas were abused to intoxicate their minds. Also, commonly abused substance in the study area include codeine, cannabis, cough syrups, rafenol, tramadol, heroin, steroids, mandrax and cocaine, alcohol, designer/ club drugs. However, types of locally made organic abused substances were sniffing or smoking dry lizard faeces, dry human faeces and dry faeces from other animals to intoxicate themselves. The study was able to establish that some delinquents inhaled the odour of contaminated water from the gutter or drainage, inhaling the odour from pit toilets and sand from gutter to make them high or intoxicated. Zakami (Daturametel) was the most abused concoction in Zaria metropolis. The juvenile delinquents (both male and female who are involved in the abuse of concoctions are combining two or more concoctions to intoxicate themselves. The place where juvenile delinquents used for substance abuse include uncompleted buildings, their rooms, bushy areas, specific spots where illicit substances are sold, nooks, premises of motor parks and inside for substance abuse. Furthermore, the methods used to abuse substances were by drinking, smoking, inhaling, injecting, chewing, sniffing, swallowing, and mixing with food or beverage drink and combination of two or more methods (Yunusa, 2016).

In a study conducted by Hali (2017), on the predisposing factors of substance abuse among women in Kano Metropolis, found that factors that predispose women to substance abuse are parental negligence, over protection by parents, having parents/guardians who are substance abusers, substance availability, to reduce tension, peer group pressure, early marriage, due to the negative influence of western media, frustration, depression and cowives rivalry. Furthermore, women abuse substances to either increase or decrease their performance. It was found that some of the women abused substances to control their emotions, especially their sexual urge when their husbands are away. It induces sleep and also keeps them calm. The study established that substance mainly abused by women in Kano metropolis were cough syrup/Roche. Others include cannabis, rafenol, tramadol, alcohol prescriptive drug etc. Also, cocaine and steroid are least abused by women in Kano metropolis (Hali,2017).

\section{Commonly Abused Drugs}

Most of the drugs that are commonly abused have been tagged "controlled substances" because of the capacity of such drugs to enhance dependence and have the potentials for abuse. For the purpose of this paper, commonly abuse drugs are narcotics, stimulants, hallucinogen and LSD, cannabis saliva, sedatives and hypnotics (depressants),as well as alcohol, tobacco and other drugs. There are three methods through which substances can be used. These are oral, injected, through inhalation (drugs like cocaine, nicotine and organic solvents are often inhaled to get high) and through intravenous or intramuscular injection delivers the drugs to the body rapidly.

Narcotics: this is used for pain relief and it is associated with surgery, terminal illness such as cancer. Initially, it is restricted to treatment in the hospital. Narcotic drugs include opium, morphine, heroin, codeine and pedthidine (Balogun, 2003).These drugs relieve pain, induce sleeping and they are addictive. 
Stimulants: are substances that have the effects of sustaining activities, thwarting sleep and masking symptoms of fatigue to the extent where death may occur because of exhaustion. Stimulants are often taken for alertness, wakefulness, excited and feeling of euphoria. There are three major sub-groups of stimulants. They are amphetamines, caffeine and cocaine. These substances act directly and stimulate the central nervous system of a human body.

Amphetamines: are stimulants of the central nervous system. The function is to replace lost energy and diminish fatigue. The abuse or overdose of the drug causes agitation, perspiration, dilated pupils, tremors, excessive talkativeness, hallucinations, high blood pressure and increased heart rate (Irambiya, 2007). In Nigeria today, the main sources of caffeine are kola nuts, coffee, tea, bitter cola, soft drink and beverages made from coca. Each of these substances contains different level of caffeine. Kolanut with a high level of caffeine is widely consumed in Nigeria, especially in the Northern part of the country. Kolanut has a pride of place in many ethnic groups during social, cultural or religious festivities among the Ibo and the Yoruba as revealed by many scholars (Balogun,2003; Soyemi, 2003 and Irambiya,2007).

Cocaine: is a stimulant. Users of cocaine experience a higher sense of euphoria, increase alertness and energy, decrease need for sleep and food. The addicts are more willing to maintain a regular supply of cocaine even with its exorbitant expense. Whatever risks that may be involved; addicts are bent to satisfy their cravings for the stuff. When there is a withdrawal, there are symptoms of apathy, sleep, depression, irritability and disorientation (Irambiya, 2007).

Hallucinogens: are drugs that cause intense effects on the mental process of perceptions, thought and feelings. Delusions, visual and psychotic behaviour results from their abuse. They are called psychedelic Drugs. Example include mescaline (derived from the mescal cactus) and LSD (lysergic acid diethylamide). These drugs are usually in tablet or capsule form. Hallucinogens produce a sense of detachment, euphoria and a reduction in sensitivity to pain. These drugs often change the way users see, hear and feel (Balogun, 2003 and Soyemi, 2003).

Cannabis Sativa (popularly known as Indian hemp): is the oldest and, most commonly abused drug in Nigeria. The term is equivalent to marijuana or marihuana, which refers to both the whole plant and the smokable parts. It contains more cancer causing agents than tobacco. Cannabis is a depressant, the consumption of which usually produces a state of euphoria similar to milder intoxication. Cannabis is a depressant and when smoked, its chemical agent reaches the brain in seconds and the effects are felt for hours. The effects of cannabis depend on the dose taken, experience, the setting, motivation, expectation and personality of the users. It damages the immune system, thereby exposing smokers to attacks by diseases (Soyemi 2003; Siro,2008).

Alcohol: is a nervous system depressant. It produces symptoms that increase in severity as its level in theblood rises.

Serious health problems that are related to chronic heavy drinking include cardiomyopathy (a disease of the heart muscles), ulcers, nutritional deficiencies, memory loss, lowered resistance to infection, and various cancers. Other alcohol- related problems include traffic and other accidents, dangerous reactions from the combination of alcohol with other drugs.

Tobacco: is derived from the dried leaves of the tobacco plant. Tobacco contains three dangerous chemicals, namely, nicotine, tar and carbon dioxide, which is the active ingredient in tobacco products. It is very addictive. Despite scientific evidence that smoking is harmful to health, some adolescents (male and female) continue to smoke in Nigeria, Although smoking was initially considered a male prerogative, changes in the roles and selfimage of women have contributed to their increased smoking. Adolescent girls now see smoking as a matter of class. Cigarette is served at night parties just like sweets. As a female, if you smoke, you are respected among peers. From the medical point of view, smoking increases the risk of coronary heart disease, lung cancer, increased heart rate, blood pressure and constriction of blood vessels.

Tobacco is another substance that is easily being abused by many. It could be taking in different forms; it can be smokeable, chewable and snuffable. Osu in Piwana and Haggai (2007) points out that tobacco is a narcotic, which affects the nervous system by stimulating it.

Inhalants: they inhale certain gases or vapours of some volatile substances, which produce depression of the central nervous system leading to euphoria or hallucinations. 
This includes petrol, glue and correction fluid, paint thinner, nail polish remover, rubber solution, aerosols propellants and nitrous oxide. They are normally inhaled through the nose or mouth. These chemicals produce intoxicating effects, thereby making abusers to feel 'high '(Balogun, 2003 and Soyemi,2003).

Abuse of various local plants has been reported in the studies, among the youth and the unemployed. These include smoking of pawpaw leaves and the seeds of zakami, which grows widely in most of the North Western and North Central regions of Nigeria. Overall, the age of first use and pattern of abuse confirms the 10-29 years' age as the most vulnerable group in drug abuse in Nigeria (UNDCP Information Series No.7, 2000).

Minor Tranquilizers: this group of drugs produces calmness without bringing drowsiness, they are mainly derived from Librium, valium etc.

Sedatives: these drugs are among the most widely abused. This is largely due to their power of relieving stress and anxiety. Some members of this drug family induce sleep, ease tension and cause relaxation. They also provide amnesia (temporary loss of memory) for users to be able to forget their problems. Their sources include valiun5/10, alcohol, promethazine, chloroform and cannabis (Siro, 2017).

Codeine: Codeine or 3-methylmorphine is the most commonly consumed opiate worldwide. It is widely used for its analgesic, anti-tussive and anti-diarrhoeal properties (Tremlettet al.,2010; Derry et al., 2013). Codeine exists as a base and several salts, but is used mainly in hydrated forms (Braun et al.,2014). Its uses and formulations vary in different countries, as do the laws that control its supply. In most countries, 'over the-counter' supply varies from total prohibition to minimal regulation on supplies from community pharmacies.

Over the counter codeine based products contain typically between 8 and 15mg of codeine per tablet, and may be marketed as a single ingredient drug or more commonly in combination with non-steroidal anti-Inflammatory agents such as ibuprofen (e.g. Nurofen Plus $\left.{ }^{\circledR}\right)$, aspirin, paracetamol, caffeine and buclizine in order to enhance the synergistic effect of drug compounds (Tremlettet al., 2010). Codeine containing cough syrups (CCCS) are amongst the most common opiate drugs and are claimed to be effective in the management of certain cough. However, it has a high potential for abuse and may present some serious adverse reactions to the user. For these reasons, access to CCCS has been restricted in Nigeria and several other countries. In fact, with the alarming rate of abuse of cough syrup containing codeine, the Federal Government of Nigeria banned the sale and importation of codeine with effect from April, 2018. The task of ensuring compliance rest with the Pharmacy Council of Nigeria and National Agency for Food and Drug Administration and Control (NAFDAC).

\section{Factors Responsible for Substance Abuse}

Almost everyone, directly or indirectly, comes in contact everyday with drug use or abuse. The drug scene is a varied one that includes licit and illicit drugs, street drugs, prescription drugs, over- the-counter drugs, drugs for pleasure, and drugs to ease pain. Drugs are used for a variety of reasons. The pharmacological action of a drug, the mind-set of the user and the setting are among the factors that determine how an individual will respond to the drugs. People give many reasons for using all kinds of psychoactive drugs. Hallucinogens (like LSD and marijuana) are especially appealing to people who believes such substances can help them achieve a better understanding of themselves or who hope to enhance their creativity. Other people use these and other psychoactive drugs hoping to avoid the feeling of powerlessness and ineffective in a complicated world. Other reasons for drug use, misuse or abuse includes desire for physical satisfaction; physical relaxation; relief from sickness; desire for more energy; desire to stimulate the senses; sexual stimulation; relief from psychological problems; relief from bad moods; relief from anxiety; to gain peer acceptance; to solve personal problems; to promote social change; to escape boredom; to study better and to improve creativity. Availability of the drugs is one of the factors responsible for substance abuse. Market is readily available. In Nigeria, the drug business is the most profitable, which make marketers and abusers hard to quit the circle.

\section{Implications of Substance Abuse}

Drugs are used for a variety of reasons. A number of effects were established by a number of researches. Physical effects of substance abuse include liver cirrhosis, pancreatic, peptic ulcer, hypertension, neurological disorder, tuberculosis, etc. Also, mental effects consist of retardation, growth deformity, nervous system deficiency, delayed motor development, amnesia and dementia among others (Mba, 2008). The various consequences of drug addiction or drug abuse are so devastating and very shameful to the extent that both the nation and international organizations all over the world are also worried about the spread of this scourge among the youths. 
They are as follows: Mental disorder, social violence, gang formation, cultism, armed robbery, 419 syndrome, internet frauds, social miscreants (area boys and girls) lawlessness among youths, lack of respect for elders, rape, loss of senses, instant death and wasting of precious and innocent lives and many more (Dankani, 2012).

The effect produced by smoking tobacco depends on the nicotine that is absorbed from the smoke. Many of the students graduate from tobacco smoking to Marijuana smoking, which they believe it will be more powerful on them and make them hyperactive. It is cheap and can easily be purchased from drug peddlers that are increasingly targeting the youth, as a symbol of revolution. Drug addicts may become a nuisance to the society, problems to themselves and their family members. There are distinct changes in the physical appearance, behavior and the general health of an addict. Such changes may include emaciated and malnourished look, neglect of personal hygiene and unkempt appearance. From homes, drug addicted adolescents associate with fellow addicts. Drug habit is not only expensive, it is also difficult to sustain.

The social problem of substance abuse among the youth (male and female) has in most cases resulted in low, moderate and high physical and psychological dependence leading to a complete withdrawal from schools and the emergence of future criminals and illiterates in the society (Schmalleger,2006; Fareo, 2012).

Similarly, the side effects of codeine over use involve: loss of pleasure in favorite activities and hobbies, lack of will in doing simple things in life, indifference toward family, events, or loved ones, decreased interest in sex and affection, loss of professional or personal drive, unawareness of how behavior and emotional distress. Additional signs of clinical depression include: anger, emptiness, irritability and sadness, or self-criticism, loss of appetite, fitful sleep, lack of sexual drive, increased erectile dysfunction (Dankani, 2012).

Apart from the aggravated side effect there is also the common adverse codeine side effects include constipation, dizziness (orthostatic hypotension), drowsiness ,dry mouth,erectile dysfunction, euphoria ,headache,sleeplessness (insomnia), itching, rash, lack of sexual drive,nausea, vomiting,pinpoint pupils (miosis), sweating,urinary retention (Dankani, 2012).

\section{Conclusion}

Drug abuse in Nigeria has come to be regarded as one of the most challenging social problems facing the nation. Indeed the very word drug inspires strong emotions and opinion among a significant number of members of the society who perceive the drug problem, as a major threat particularly to its younger members. From time immemorial, man has in the hope of alleviating physical pain or altering state of consciousness used various substances. Societies all over the globe have discovered some intoxicants that affect the centralnervous system, relieving physical and mental anguish or producing euphoria. Different factors have been identified as the cause of drug abuse. Some use drugs for medication; others use them to satisfy curiosity, while still others use them to copy assumed idols or significant persons. As friends move together, they discuss freely, thereby learning a lot of things that are both desirable and undesirable from one another. However, a person may wrongly start using drugs on his or her own, and then select friends who are doing the same or may direct others to imitate him or her. Use of drugs continues in spite of harm to the user and society.

\section{Recommendations}

- Ministry of education (Federal and State) must as a matter of urgency add to their curricular 'Drug Education.' Drug education will help youths adopt positive attitudes, values, behaviours, skill and life-styles that will enable them to mature into happy and competent citizens who need not resort to the use of drugs as problem solvers; thus contributing maximally to national development.

- The Federal government should incorporate lessons on the effects of substance abuse in the school curriculum from primary school to tertiary level of education.

- The State and Local governments should ban joints and recreational centers known to be selling points for illicit substances and ensure that uncompleted buildings that are hide-out for the consumption and sale of illicit substances are completed by the owners or risk demolition.

- Every member of the community should work in collaboration with the government to report all illegal drug sellers to the National Drug Law Enforcement Agency (NDLEA) or the police so that they can be arrested and prosecute by the authority. 
- Parents should carefully monitor their children and should prevent them from making friends with bad peer groups and they should always advise their children at home, show them love, care and encourage them through religious and western education to understand the effects substance abuse.

- NAFDAC and NDLEA should as a matter of urgency intensify its efforts by monitoring drug distribution within the country as well as dealing with chemists and pharmacies that disregard its directives on controlled drugs.

- Considering the magnitude of the problem Government should establish special Drug Rehabilitation Centers to attend to victims of drug abuse.

- NAFDAC and NDLEA should embark on grassroots awareness creation and sensitization campaign to warn the public of the risks of abuse/misuse of codeine containing medicinal products.

\section{References}

Abdullahi,S.A.(2003), The Use of Traditional Drugs amongst the Kano Youth: The Case of 'Gadagi' in A. Garba (ed) Youth and Drug Abuse In Nigeria; Strategies for Counselling, Management and Control, Kano: Matasa Press.

Ayatse, J. S. (2005) Cultism in Nigerian Educational Institution. Makurdi:Oracle Business Limited.

Balogun, P.O. (2003), "Drug Abuse among the Youths: A Persistent Social Problem." A Paper presented at the Command and Staff College Jaji, Kaduna.

Braun, D. E. etal (2014), Insights into Hydrate Formation and Stability of Morphinanes from a Combination of Experimental and Computational Approaches.Molecular Pharmaceutics, 11(9), 3145-3163.

Dankani, I.M. (2012),Abuse of Cough Syrups: A New Trend in Drug Abuse in Northwestern Nigeria States of Kano, Sokoto,Katsina,Zamfara and Kebbi.International Journal of Physical and Social Sciences. Volume 2, Issue 8, August.

Derry, S., Karlin, S. M., \& Moore, R. A. (2013).Single Dose Oral Ibuprofen plus Codeine for acute Postoperative Pain in Adult.The Cochrane Databaseof Systematic Reviews, Issue 3.

Emmanuel, O. (2013), Religious Imperatives as Panacea to Crime and Violence among Youths in Nigeria. European Journal of Business and Social Sciences 2(8): 12-22.

Fareo, D. (2012),Drug Abuse among Nigerian Adolescents: Strategies for Counselling. Journal of International Social Research 5(12):341-347.

Haladu, A.A.(2003), Outreach Strategies for Curbing Drug Abuse among outof School Youth in Nigeria: A Challenge for Community Based Organizations (CBOs), in in A.Garba (ed) Youth and Drug Abuse in Nigeria;Strategies for Counselling, Management and Control, Kano:Matasa Press.

Hali,M. (2017), The Predisposing Factors of Substance Abuse among Women in

Kano Metropolis.(unpublishedM.Sc dissertation),Department of

Sociology, Bayero University, Kano- Nigeria.

Irambiya, M. I. (2007), Drug Problems: The Law and Nigerian Society. Fab Educational Books, Jos - Nigeria.

Mba, A.I. (2008), Counsellling Techniques for the rehabilitation of Drug Addicts in Nigeria. The Counsellor, 18(1) pp10 -18.

NAFDAC (2004), A handbook on Prevention of Drugs and Substance Abuse in Nigeria.

NAFDAC (2010), Important Drug Information about Cough Syrups containing Codeine. A news bulletin Abuja.

Okeshola, B.F.(2009), a Study of Drug Abuse Among Commercial Motorcyclists in Zaria, Kaduna State.LapaiInternational Journal of Management Social Sciences Vol.2 No.2, December.

Oluremi,F.D. (2012),Drug Abuse among Nigerian Adolescents: Strategies for Counselling. The Journal of International Social Research, 5(20), 341 -347.

Oshikoya, K. A. and Alli, A. (2006) Perception of drug abuse amongst Nigerian Undergraduates. World Journal of Medical Sciences. Vol.1. No.2. P133-139.

Piwana, C. N. \& Haggai, M. P. (2007)" Drug abuse and Cultism in higher Institution of learning”.The Case Study of University of Jos.

Schmalleger,F.(2006), Criminology Today: An Integrative Introduction. Third edition., New York Prentice Hall Publishers.

Siro, A.A.(2008), A Sociological Study of Drug Abuse among the Youth in Kano (unpublished M.Sc dissertation), Department of Sociology, Bayero University, Kano- Nigeria. 
Siro, A.A.(2014),Drug Abuse and Political Thuggery among Youth in KanoMetropolis: A Civilization or Resource Management? Journal of Studies in Social Sciences, 7(2),144 -163.

Siro, A.A.(2017), Drug Abuse: A Generic Urban Kano Partial east Square(PLS) Analysis in Dutse Journal of Criminology and Security Studies. Vol.1,No.1, pp115 -134.Printed by Yehison Nigeria Limited, Nigeria.

Soyemi,O.A. (2003), Drug- Related Crimes in Nigeria. The Way Forward.A Paper Presented at the Command and Staff College Jaji, Kaduna.

Tremlett, M., Anderson, B. J., \& Wolf, A. (2010),Pro-con debate: is Codeine a Drug that still has a Useful Role in Pediatric Practice? Pediatric.UNDCP Information Series No.7, 2000.

Utman, G.S.Shallangwa, J.J., Talba, F.B. and .Zakama, S.G ( 2017), A Survey of the Usage and Users of Codeine Containing Cough Syrups (CCCS) in KadunaMetropolitan Area of Northern Nigeria. Nigeria Journal Pharmaceutical Science, March.

Yunusa, A. (2016), The Nature of Substance Abuse among Juvenile Delinquents in Zaria Metropolis of Kaduna State. A Journal of SociologicalStudies.Vol.2,No.1,July. Published by Department of Sociology, Bayero University, Kano -Nigeria.

Yusuf F.A.(2010),Factors Influencing Substance Abuse among Undergraduate Students in Osun State. An International Multi-Disciplinary Journal, Ethiopia.Vol. 4 (4), Serial No. 17, October. 